\title{
The Reproducibility of Indoor Air Pollution (IAP) Measurement: A Test Case for the Measurement of Key Air Pollutants from the Pan Frying of Fish Samples
}

\author{
Ki-Hyun Kim, ${ }^{1}$ Yong-Hyun Kim, ${ }^{1}$ Bo-Won Kim, ${ }^{1}$ Jeong-Hyeon Ahn, \\ Min-Suk Bae, ${ }^{2}$ and Richard J. C. Brown ${ }^{3}$ \\ ${ }^{1}$ Department of Civil \& Environmental Engineering, Hanyang University, 222 Wangsimni-Ro, Seoul 133-791, Republic of Korea \\ ${ }^{2}$ Department of Environmental Engineering, Mokpo National University, Mokpo 534-729, Republic of Korea \\ ${ }^{3}$ Analytical Science Division, National Physical Laboratory, Teddington TW11 OLW, UK \\ Correspondence should be addressed to Ki-Hyun Kim; kkim61@hanyang.ac.kr
}

Received 1 April 2014; Revised 27 May 2014; Accepted 27 May 2014; Published 25 June 2014

Academic Editor: Guor-Cheng Fang

Copyright (C) $2014 \mathrm{Ki}$-Hyun Kim et al. This is an open access article distributed under the Creative Commons Attribution License, which permits unrestricted use, distribution, and reproduction in any medium, provided the original work is properly cited.

\begin{abstract}
To assess the robustness of various indoor air quality (IAQ) indices, we explored the possible role of reproducibility-induced variability in the measurements of different pollutants under similar sampling and emissions conditions. Polluted indoor conditions were generated by pan frying fish samples in a closed room. A total of 11 experiments were carried out to measure a list of key variables commonly used to represent indoor air pollution (IAP) indicators such as particulate matter $\left(\mathrm{PM} \mathrm{PM}_{1}, \mathrm{PM}_{2.5}, \mathrm{PM}_{10}\right.$, and TSP) and a set of individual volatile organic compounds (VOCs) with some odor markers. The cooking activity conducted as part of our experiments was successful to consistently generate significant pollution levels (mean $\mathrm{PM}_{10}: 7110 \mu \mathrm{g} \mathrm{m}^{-3}$ and mean total VOC (TVOC): $1400 \mu \mathrm{g} \mathrm{m}^{-3}$, resp.). Then, relative standard error (RSE) was computed to assess the reproducibility between different IAP paramters measured across the repeated experiments. If the results were evaluated by an arbitrary criterion of $10 \%$, the patterns were divided into two data groups (e.g., $<10 \%$ for benzene and some aldehydes and $>10 \%$ for the remainders). Most noticeably, TVOC had the most repeatable results with a reproducibility (RSE) value of $3.2 \%(n=11)$.
\end{abstract}

\section{Introduction}

The paradoxical aspect of cooking (that it is simultaneously necessary for human life but also exposes us to the risk of hazardous pollution) is an intriguing issue in environmental science. Cooking with fire generally releases many deleterious substances from the food and the fuels used for combustion. The types of pollutants released from these sources include particulate matter (PM) and the associated components (e.g., metals, polycyclic aromatic hydrocarbons (PAH), etc.) and gaseous constituents (e.g., carbon monoxide, formaldehyde, nitrogen dioxide, and volatile organic compounds) [1]. If these pollutants are not properly ventilated or treated, cooking activities can be considered the primary source of indoor air pollution (IAP) and pose significant threats not only to those who are cooking but also to those who reside in the same facility.
In light of the environmental significance of cooking activities and associated IAP, much research has been conducted to elucidate the effect of air pollutants released from cooking on human health. For instance, the associations between methods of cooking meats and colorectal cancer were assessed in a study performed in Stockholm in 19861988 [2]. If the significance of each variable (e.g., total meat intake, cooking style, etc.) was assessed based on the relative risks (RR) in relation to cancer type (colon versus rectum), the highest risks were found from fried meat with a heavily browned surface $(\mathrm{RR}$ colon $=2.8, \mathrm{RR}$ rectum $=6.0$ ). Similarly, dose-response relationships between cooking fume exposure and lung cancer were investigated among nonsmoking Chinese women [3]. These authors relied on multiple unconditional logistic regressions to estimate the odds ratios (OR) for different levels of exposure, after adjusting for various potential confounding factors. They concluded that 
TABLE 1: Physicochemical properties of the target compounds investigated in this study.

(a) Gaseous VOCs

\begin{tabular}{lcccccccc}
\hline Order & Group & Compounds & Short name & $\mathrm{MW}\left(\mathrm{g} \mathrm{mol}^{-1}\right)$ & Density $\left(\mathrm{g} \mathrm{cm}^{-3}\right)$ & Boiling point $\left({ }^{\circ} \mathrm{C}\right)$ & Formula & $\mathrm{CAS}$ number \\
\hline 1 & & Formaldehyde & FA & 30.03 & 0.8153 & -19 & $\mathrm{CH}_{2} \mathrm{O}$ & $50-00-0$ \\
2 & & Acetaldehyde & AA & 44.1 & 0.785 & 20.2 & $\mathrm{C}_{2} \mathrm{H}_{4} \mathrm{O}$ & $75-07-0$ \\
3 & \multirow{2}{*}{ Aldehyde } & Propionaldehyde & PA & 58.1 & 0.798 & $46-50$ & $\mathrm{C}_{3} \mathrm{H}_{6} \mathrm{O}$ & $123-38-6$ \\
4 & & Butyraldehyde & $\mathrm{BA}$ & 72.1 & 0.805 & 74.8 & $\mathrm{C}_{4} \mathrm{H}_{8} \mathrm{O}$ & $123-72-8$ \\
5 & & Isovaleraldehyde & IA & 86.1 & 0.797 & $90-93$ & $\mathrm{C}_{5} \mathrm{H}_{10} \mathrm{O}$ & $590-86-3$ \\
6 & & n-Valeraldehyde & VA & 86.1 & 0.81 & $102-103$ & $\mathrm{C}_{5} \mathrm{H}_{10} \mathrm{O}$ & $110-62-3$ \\
\hline 7 & & Benzene & $\mathrm{B}$ & 78.11 & 0.878 & 80.1 & $\mathrm{C}_{6} \mathrm{H}_{6}$ & $71-43-2$ \\
8 & & Toluene & $\mathrm{T}$ & 92.14 & 0.866 & 111 & $\mathrm{C}_{7} \mathrm{H}_{8}$ & $108-88-3$ \\
$9-1$ & Aromatic & p-Xylene & p-X & 106.2 & 0.865 & 138 & $\mathrm{C}_{8} \mathrm{H}_{10}$ & $106-42-3$ \\
$9-2$ & & m-Xylene & m-X & 106.2 & 0.865 & 139 & $\mathrm{C}_{8} \mathrm{H}_{10}$ & $108-38-3$ \\
$9-3$ & & o-Xylene & $\mathrm{o}-\mathrm{X}$ & 106.2 & 0.88 & 144 & $\mathrm{C}_{8} \mathrm{H}_{10}$ & $95-47-6$ \\
10 & & Styrene & $\mathrm{S}$ & 104.2 & 0.906 & 145 & $\mathrm{C}_{8} \mathrm{H}_{8}$ & $100-42-5$ \\
\hline 11 & Ketone & Methyl ethyl ketone & $\mathrm{MEK}$ & 72.11 & 0.805 & 79.64 & $\mathrm{C}_{4} \mathrm{H}_{8} \mathrm{O}$ & $78-93-3$ \\
12 & Ester & n-Butyl acetate & $\mathrm{BuAc}$ & 116.2 & 0.881 & 126 & $\mathrm{C}_{6} \mathrm{H}_{12} \mathrm{O}_{2}$ & $123-86-4$ \\
\hline
\end{tabular}

(b) Others

\begin{tabular}{lcc}
\hline Order & Name & Short name \\
\hline 1 & Total suspended particulate & $\mathrm{PM}_{\text {total }}$ \\
2 & Particulate matter 1 & $\mathrm{PM}_{1}$ \\
3 & Particulate matter 2.5 & $\mathrm{PM}_{2.5}$ \\
4 & Particulate matter 10 & $\mathrm{PM}_{10}$ \\
\hline 5 & Total volatile organic compounds & TVOC \\
\hline
\end{tabular}

the risk of lung cancer in their target subjects was increased by cumulative exposure to any form of cooking by frying.

It is important to define indoor air pollutants currently of interest in order to inform the species to be measured by this study. For instance, a total of nine common indoor air pollutants (carbon dioxide, $\mathrm{CO}_{2}$; carbon monoxide, $\mathrm{CO}$; respirable suspended particulates, RSP; nitrogen dioxide, $\mathrm{NO}_{2}$; ozone, $\mathrm{O}_{3}$; formaldehyde, $\mathrm{HCHO}$; total volatile organic compounds, TVOC; radon, Rn; and airborne bacteria count, $\mathrm{ABC}$ ) were officially selected as the parameters used in a certification scheme for office/public IAQ assessment in Hong Kong [4]. Often researchers rely on a reduced number of pollutants as markers for the full suite of possible indoor air pollutants. For instance, [4] the selected three (RSP, $\mathrm{CO}_{2}$, and TVOC) parameters based on such selection criteria include test sensitivity, specificity, and predictability.

The main objective of this study is to measure how reproducible pollutant concentration levels are, when the same source activity (i.e., pan frying of mackerel) is repeated at the same place but at different times. This gives some information about which IAP variables can be determined most consistently despite the presence of confounding sources of bias and variability (e.g., preparation of fish sample, cooking conditions, sampling, and analysis). The results of our study are thus expected to offer some insights into the most stable indoor air pollutants which could also be used as markers of pollution in assessing indoor environments.

\section{Materials and Methods}

2.1. Selection of Food Material and Target Components. In this work, we investigated a list of key pollutants that can be released from pan frying of fish, a common foodstuff in many countries. Indeed mackerel is one of the most common fish commercially available in Korean market places for its low price and unique taste favored by Koreans. Hence, we selected raw mackerel fish for pan frying. This has the additional benefit that its cooking can easily generate oil fumes and related pollutants.

To measure the pollutants released during pan frying, we focused on a list of volatile organic compounds (VOCs) that are well known as indoor pollutants and key offensive odorants such as acetaldehyde (AA), formaldehyde (FA), benzene (B), and TVOC [5]. Additionally, particulate matter in several size fractions (total suspended particulate (TSP), $\mathrm{PM}_{1}, \mathrm{PM}_{2.5}$, and $\left.\mathrm{PM}_{10}\right)$ and some odorous VOCs $(n=9)$ were also measured. The basic physicochemical properties (e.g., chemical formula, structural formula, molecular weight, CAS number, etc.) of all these compounds $(n=17)$ are summarized in Table 1 . The basic information concerning sample collection and analysis of these target compounds is summarized in Table 2. In addition, detailed information of analytical procedures used for each air component is described in Table 2(d) along with operation conditions for all instrumental systems. 


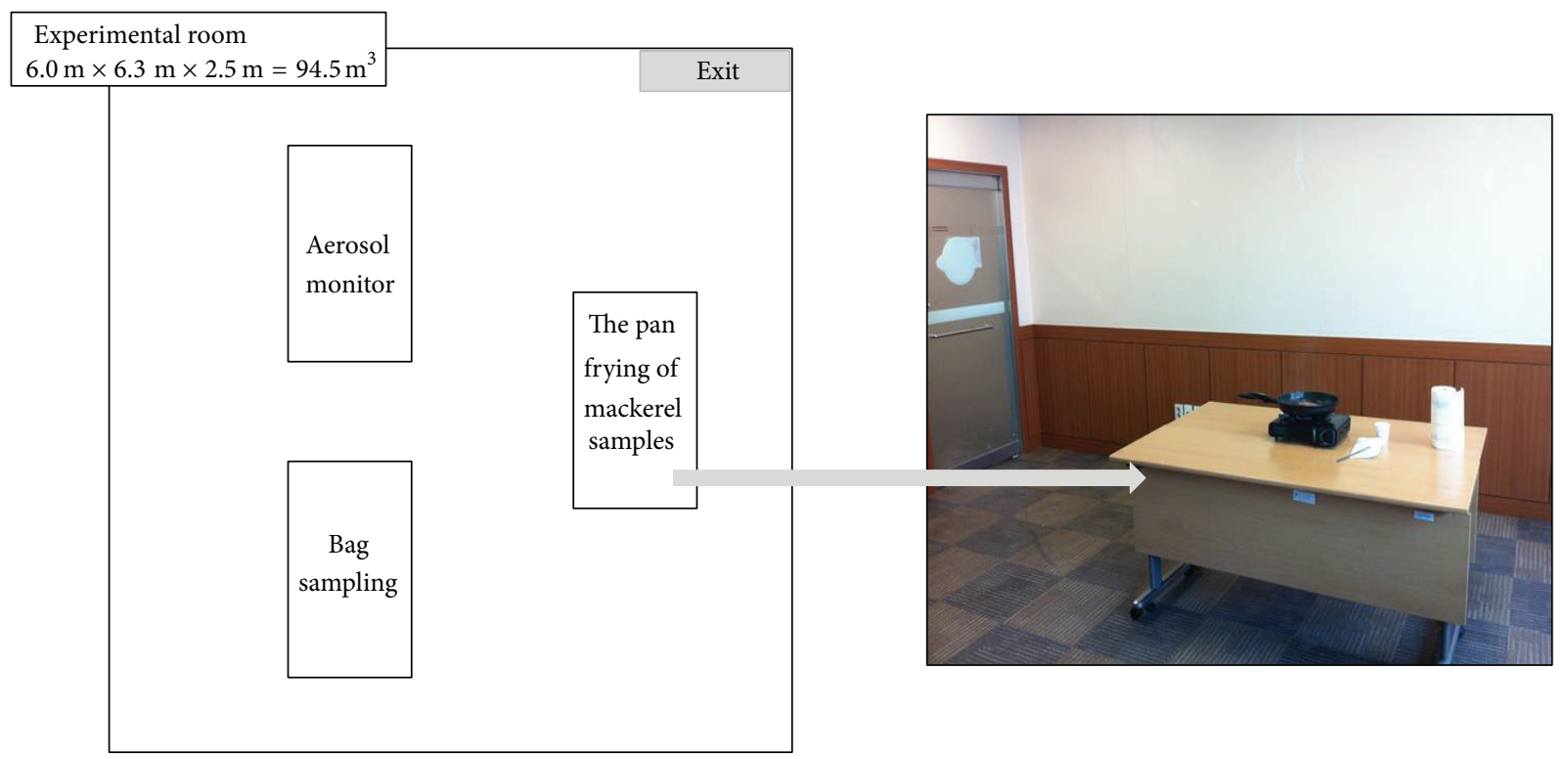

(a) Experimental room
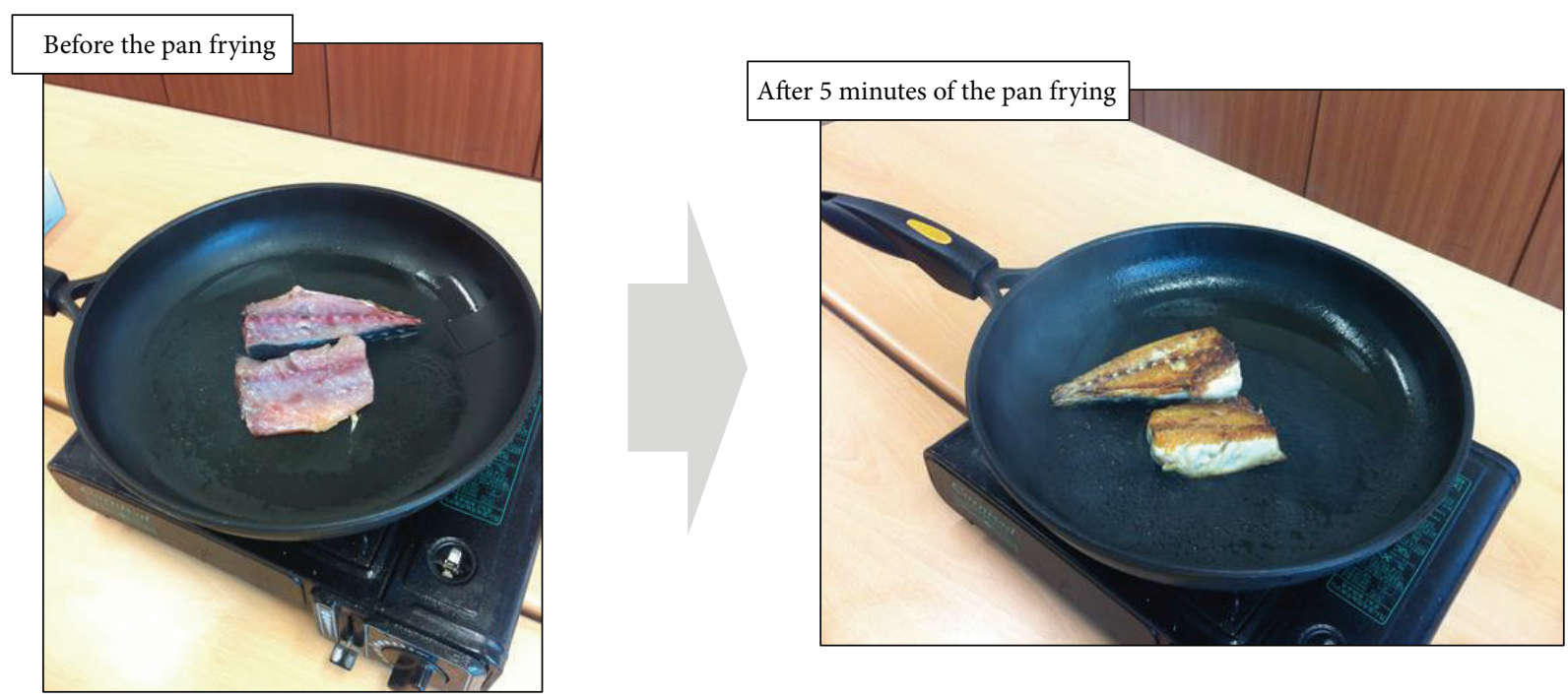

(b) Mackerel sample before and after the pan frying

FIGURE 1: Photographs showing the mackerel samples investigated in this study.

2.2. Sample Collection. For the purpose of this study, all mackerel samples were purchased fresh from a local market on the day of the experiment for the pan frying as discussed below. A total of 11 experiments were carried out over a three-day period in January 2014 (Table 2). All sampling was conducted in a room with capacity of $94.5 \mathrm{~m}^{3}(6.0 \mathrm{~m} \times 6.3 \mathrm{~m}$ $\times 2.5 \mathrm{~m}$ (height)) (Figure 1 ). The temperature of the room ranged from 15 to $17^{\circ} \mathrm{C}$ during a sampling period over the three days. For each experiment, the new mackerel samples (approximately $200 \mathrm{~g}$ ) were pan fired intensively for five minutes at the maximum flame setting on a portable grill using liquefied petroleum gas (LPG) without any additional oil or condiments. A significant amount of fumes and particulates appeared to be produced during these five minutes. The pan was placed on a desk (width: $0.6 \mathrm{~m}$, length: $2 \mathrm{~m}$, and height:
$0.8 \mathrm{~m}$ ). Sampling points were placed $1.5 \mathrm{~m}$ (vertically) and $2.5 \mathrm{~m}$ (horizontally) away from the pan.

The bag sampling and the measurement for PM data started immediately after turning off the portable grill (after 5 minutes of frying). Polluted air samples were then collected immediately into $10 \mathrm{~L}$ polyester aluminum (PEA) bags using a lung sampler (ACEN Co. Ltd., Korea). Upon collection of each sample, all windows and doors were opened to ventilate the polluted air before the next experiment. Because of this long ventilation requirement, the experiments were carried out at roughly three-hour intervals. The basic environmental conditions for each experiment are described in Table 2. All of the bag samples were then subjected to the GC-MS analysis for the target compounds. Concentrations of PM were measured in real time using aerosol monitor (Dusttrak 
TABLE 2: Details of the sample, sampling, and analytical system for the analysis of smoke released from mackerel samples.

(a) Information of mackerel sample

\begin{tabular}{|c|c|c|c|c|c|}
\hline \multirow{2}{*}{ Order } & \multirow{2}{*}{ Sample code } & \multirow{2}{*}{ Weight (g) } & \multirow{2}{*}{ Room Temperature $\left({ }^{\circ} \mathrm{C}\right)$} & \multicolumn{2}{|c|}{ Sampling } \\
\hline & & & & Date & Time \\
\hline 1 & M1 & 192 & 15.3 & 27 Jan. 2014 & $10: 03$ \\
\hline 2 & M2 & 169 & 17.0 & 27 Jan. 2014 & $13: 10$ \\
\hline 3 & M3 & 200 & 16.5 & 27 Jan. 2014 & $16: 11$ \\
\hline 4 & M4 & 194 & 16.1 & 27 Jan. 2014 & 19:03 \\
\hline 5 & M5 & 186 & 16.2 & 28 Jan. 2014 & $10: 20$ \\
\hline 6 & M6 & 167 & 16.9 & 28 Jan. 2014 & $13: 31$ \\
\hline 7 & M7 & 184 & 16.4 & 28 Jan. 2014 & $16: 07$ \\
\hline 8 & M8 & 189 & 15.8 & 28 Jan. 2014 & 19:09 \\
\hline 9 & M9 & 189 & 17.1 & 29 Jan. 2014 & $11: 08$ \\
\hline 10 & M10 & 191 & 16.5 & 29 Jan. 2014 & $14: 10$ \\
\hline 11 & M11 & 195 & 15.9 & 29 Jan. 2014 & 17:07 \\
\hline
\end{tabular}

(b) Information of sampling

\begin{tabular}{lc}
\hline (1) Target compounds: & Gaseous VOCs $(n=12)$ \\
(2) Sampling approach: & Lung sampling \\
(3) Sample container: & 10 L polyester aluminum (PEA) bag \\
(4) Sampling flow rate: & $20 \mathrm{~L} \mathrm{~min}^{-1}$ \\
(5) Sampling time: & $0.5 \mathrm{~min}$ \\
(6) Sample volume: & $10 \mathrm{~L}$ \\
\hline
\end{tabular}

(c) Analytical method

\begin{tabular}{|c|c|c|c|c|}
\hline Order & Target compounds & Pretreatment & Separation system & Detector \\
\hline 1 & Particulate matters $(n=4)$ & - & - & $\begin{array}{c}90^{\circ} \text { light-scattering laser } \\
\text { photometer }\end{array}$ \\
\hline \multirow{2}{*}{2} & FA & \multirow{2}{*}{ DNPH-cartridge } & HPLC: Acclaim 120 & \multirow{2}{*}{ UV } \\
\hline & $\mathrm{AA}$ & & $\mathrm{C} 18$ & \\
\hline \multirow{4}{*}{3} & Aldehyde (4) & \multirow{4}{*}{$\begin{array}{c}\text { Sorbent tube/thermal } \\
\text { desorption }\end{array}$} & \multirow{4}{*}{$\begin{array}{c}\text { GC: wax column } \\
(30 \mathrm{~m} \times 0.25 \mathrm{~mm} \times \\
0.25 \mu \mathrm{m})\end{array}$} & \multirow{4}{*}{$\begin{array}{l}\text { Quadrupole mass } \\
\text { spectrometry }\end{array}$} \\
\hline & Aromatics (4) & & & \\
\hline & Ketone (1) & & & \\
\hline & Ester (1) & & & \\
\hline
\end{tabular}

(d) Operational description of two instrumental systems (HPLC and GC) in this study

(A) HPLC/UV (Spectrasystem UV2000, Thermo scientific, USA) system for carbonyl compounds analysis
(i) Injector
(iii) Detector (UV)

Volume:

$20 \mu \mathrm{L}$

Wavelength:

$360 \mathrm{~nm}$

(ii) Pump

Flow rate:

$1.5 \mathrm{~mL} / \mathrm{min}$

(iv) Column $\left(\mathrm{C}_{18}\right.$, Hichrom, UK)

Mobile phase:

$70: 30$ acetonitrile $: \mathrm{H}_{2} \mathrm{O}$

Length:

$250 \mathrm{~mm}$

Analysis time:

$16 \mathrm{~min}$

Diameter:

$4.6 \mathrm{~mm}$

Particle size:

$5 \mu \mathrm{m}$ 
(d) Continued.

(B) TD-GC/MS system

(1) GC (SHIMADZU GC-2010, JAPAN) and MS (SHIMADZU GCMS-QP2010, JAPAN) system

(i) Oven

$\begin{array}{lc}\text { 1st oven temperature: } & 40^{\circ} \mathrm{C}(5 \mathrm{~min} .) \\ \text { 1st oven rate: } & 5^{\circ} \mathrm{C} \mathrm{m^{-1 }} \\ \text { 2nd oven temperature: } & 220^{\circ} \mathrm{C}(5 \mathrm{~min} .) \\ & \\ \text { Total time: } & 46 \mathrm{~min} \\ \text { Carrier gas: } & \mathrm{He}(99.999 \%) \\ \text { Column flow: } & 1 \mathrm{~mL} \mathrm{~min}^{-1}\end{array}$

(ii) Detector (MS)

$\begin{array}{lc}\text { Ionization mode: } & \mathrm{EI}(70 \mathrm{eV}) \\ \text { Ion source temperature: } & 230^{\circ} \mathrm{C} \\ \text { Interface temperature: } & 230^{\circ} \mathrm{C}\end{array}$

TIC scan range:

$35 \sim 600 \mathrm{Mz}^{-1}$

(2) Thermal desorber (UNITY II, Markes International, Ltd., UK) condition

Cold trap:

Carbopack C + Carbopack B (volume ratio $=1: 1$ )

Split ratio:

$1: 5$

Split flow:

$5 \mathrm{~mL} \mathrm{~min}^{-1}$

Trap temp (low):

$5^{\circ} \mathrm{C}$

Trap hold time:

$5 \mathrm{~min}$

Trap temp (high):

$330^{\circ} \mathrm{C}$

Flow path temperature:

$180^{\circ} \mathrm{C}$

DRX 8533, TSI understanding accelerated, USA) without the sampling steps.

2.3. Analysis of Target Compounds. The compounds chosen for analysis are those regularly referred to by indoor and ambient air legislation around the world as being harmful to human health or environmental sustainability or active as ozone precursors in the atmosphere.

2.3.1. Formaldehyde and Acetaldehyde. The analysis of two aldehydes (formaldehyde (FA) and acetaldehyde (AA)) was carried out using high performance liquid chromatography (HPLC) equipped with a UV detector and dsCHROM software (for peak integration). The details of the HPLC system are summarized in Table 2. To undertake the analysis of the two aldehydes, samples in 10 L PEA bags were passed through Lp DNPH cartridges (Top Trading Co., Korea) for $5 \mathrm{~min}$ (at a fixed sampling flow rate of $1 \mathrm{~L} \mathrm{~min}^{-1}$ ) via a Sep-Pak ozone scrubber (Top Trading Co., Korea). Next, the target analytes caught up in the cartridges were eluted slowly with $5 \mathrm{~mL}$ acetonitrile and then filtered through $0.45 \mu \mathrm{m}, 13 \mathrm{~mm}, \mathrm{GHP}$ Acrodisc filters (PALL, NY, USA) into a $25 \mathrm{~mL}$ borosilicate volumetric flask. The eluant was manually injected into the HPLC system, via a $20 \mu \mathrm{L}$ sample loop. The analytical precision, if assessed in terms of RSE, was $0.43 \%$ for FA and $0.18 \%$ for AA. The method detection limits (MDL) for FA and AA were $0.32 \mathrm{ppb}$ and $0.28 \mathrm{ppb}$, respectively.

2.3.2. VOC and TVOC Analysis. A TD system interfaced with GC and mass spectrometry (MS) was used for the analysis of VOCs ((1) aldehyde $(n=4)$, (2) ketone $(n=1)$, (3) aromatics $(n=4)$, and $(4)$ ester $(n=1))$ odorants, as listed in Table 1. The detailed operating conditions of this system are given in Table 2. The analysis of the VOCs was conducted by combining a gas chromatography system (GC: SHIMADZU GC-2010, Japan) equipped with a mass spectrometry system (MS: SHIMADZU GCMS-QP2010, Japan) and a thermal desorber (TD: Markes Ltd., UK). First, the gaseous samples loaded on the sorbent tube were thermally desorbed and passed through the cold trap unit of the TD at a preconcentration of $5^{\circ} \mathrm{C}$. Then, the samples were thermally desorbed, transferred into the GC system, and separated on a CP-wax (60 m length, $0.25 \mathrm{~mm}$ diameter, and $0.25 \mu \mathrm{m}$ film thicknesses). The analysis of VOCs was performed in the following order: (1) transfer of samples loaded on the sorbent tube into the TD unit; (2) preconcentration on the cold trap by Carbopack $\mathrm{C}$ and $\mathrm{B}$ at a $1: 1$ volume ratio basis (Supelco, US) at $5^{\circ} \mathrm{C}$; (3) thermal desorption at $330^{\circ} \mathrm{C}$ for 5 min; and (4) detection by the MS. The DL values for the VOCs ranged from $0.046 \mathrm{ppb}$ (n-butyl acetate) to $0.253 \mathrm{ppb}$ (propionic aldehyde).

The concentration of TVOC $\left(\mu \mathrm{g} \mathrm{m}^{-3}\right)$ was estimated using the chromatograms obtained by the TD-GC-MS analysis. The TVOC values were calculated as the total concentrations of the target VOCs plus the nontarget VOCs found between $n$-hexane and n-hexadecane. The concentrations of nontarget VOCs were quantified using the response factor of toluene.

2.3.3. PM Analysis. The PM released from mackerel samples by the pan frying was measured using aerosol monitor (Dusttrak DRX 8533, TSI understanding accelerated, USA). The mass concentrations of each $\mathrm{PM}$ fraction $\left(\mathrm{PM}_{1}, \mathrm{PM}_{2.5}, \mathrm{PM}_{10}\right.$, and total PM) were estimated simultaneously using realtime $90^{\circ}$ light-scattering laser photometers. The sampling flow rate for the measurement of $\mathrm{PM}$ was fixed at $3 \mathrm{~L} \mathrm{~min}^{-1}$. The quantification range of the aerosol monitor was 0.001 to $150 \mathrm{mg} \mathrm{m}^{-3}$.

\section{Results and Discussion}

3.1. The Level of IAP by Pan Frying Fish Samples. In this study, a total of 11 experiments were conducted to measure a set of indoor pollutants and odorant species released 
TABLE 3: Concentrations of PM and gaseous VOCs released from mackerel samples by the pan frying.

\begin{tabular}{|c|c|c|c|c|c|c|c|c|c|c|c|c|c|c|c|c|}
\hline \multirow{2}{*}{\multicolumn{2}{|c|}{ Order Target compounds }} & \multirow{2}{*}{ Unit } & \multicolumn{14}{|c|}{ Sample code } \\
\hline & & & M1 & M2 & M3 & M4 & M5 & M6 & M7 & M8 & M9 & M10 & M11 & Mean & SD & RSE \\
\hline \multicolumn{17}{|c|}{ (a) Particulates } \\
\hline 1 & $\mathrm{PM}_{\text {total }}$ & $\mathrm{mg} / \mathrm{m}^{3}$ & 4.51 & 9.40 & 8.24 & 8.98 & 3.38 & 6.29 & 6.53 & 12.1 & 7.07 & 7.84 & 7.76 & 7.46 & 2.37 & 9.57 \\
\hline 2 & $\mathrm{PM}_{1}$ & $\mathrm{mg} / \mathrm{m}^{3}$ & 3.79 & 8.64 & 5.94 & 7.39 & 2.82 & 5.02 & 5.74 & 11.3 & 6.58 & 7.73 & 7.24 & 6.56 & 2.33 & 10.7 \\
\hline 3 & $\mathrm{PM}_{2.5}$ & $\mathrm{mg} / \mathrm{m}^{3}$ & 3.88 & 8.71 & 6.15 & 7.60 & 2.86 & 5.15 & 5.87 & 11.4 & 6.68 & 7.76 & 7.29 & 6.67 & 2.33 & 10.6 \\
\hline 4 & $\mathrm{PM}_{10}$ & $\mathrm{mg} / \mathrm{m}^{3}$ & 4.26 & 9.10 & 7.24 & 8.27 & 3.09 & 5.67 & 6.28 & 11.9 & 6.88 & 7.82 & 7.66 & 7.11 & 2.37 & 10.1 \\
\hline \multicolumn{17}{|c|}{ (b) Gaseous VOCs } \\
\hline 5 & FA & $\mathrm{ppb}$ & 39.4 & 33.4 & 24.2 & 39.8 & 18.1 & 42.0 & 40.3 & 53.0 & 38.1 & 44.8 & 23.9 & 36.1 & 10.3 & 8.61 \\
\hline 6 & AA & ppb & 105 & 138 & 52.7 & 144 & 83.9 & 153 & 73.9 & 144 & 54.1 & 85.7 & 58.2 & 99.3 & 39.2 & 11.9 \\
\hline 7 & $\mathrm{PA}$ & ppb & 1.23 & 1.84 & 16.8 & 1.74 & 1.55 & 1.84 & 19.2 & 1.63 & 27.0 & 40.6 & 30.9 & 13.1 & 14.5 & 33.3 \\
\hline 8 & $\mathrm{BA}$ & $\mathrm{ppb}$ & 5.67 & 8.62 & 3.90 & 10.8 & 4.63 & 8.45 & 5.39 & 12.5 & 8.22 & 8.87 & 8.84 & 7.81 & 2.66 & 10.3 \\
\hline 9 & IA & $\mathrm{ppb}$ & 4.67 & 5.43 & 2.57 & 4.89 & 4.16 & 5.08 & 2.74 & 5.74 & 2.03 & 3.33 & 2.93 & 3.96 & 1.29 & 9.8 \\
\hline 10 & VA & ppb & 8.94 & 12.9 & 7.73 & 13.6 & 8.88 & 13.3 & 10.1 & 17.6 & 12.5 & 14.7 & 13.9 & 12.2 & 2.97 & 7.34 \\
\hline 11 & B & $\mathrm{ppb}$ & 3.39 & 2.38 & 1.56 & 2.51 & 1.79 & 2.01 & 1.48 & 2.28 & 1.94 & 1.80 & 1.82 & 2.09 & 0.54 & 7.80 \\
\hline 12 & $\mathrm{~T}$ & $\mathrm{ppb}$ & 10.3 & 12.9 & 3.4 & 10.4 & 6.26 & 8.82 & 5.10 & 9.13 & 4.90 & 14.9 & 8.64 & 8.62 & 3.51 & 12.3 \\
\hline 13 & $\mathrm{X}$ & ppb & 2.88 & 1.86 & 0.56 & 1.31 & 0.93 & 1.29 & 0.91 & 1.64 & 0.54 & 0.67 & 0.56 & 1.20 & 0.72 & 18.1 \\
\hline 14 & S & ppb & 2.16 & 0.75 & 0.62 & 0.79 & 1.62 & 0.99 & 0.57 & 1.75 & 1.03 & 0.70 & 0.65 & 1.06 & 0.54 & 15.4 \\
\hline 15 & MEK & ppb & 2.09 & 3.09 & 0.76 & 3.12 & 1.38 & 2.30 & 0.74 & 2.35 & 1.31 & 2.39 & 2.06 & 1.96 & 0.82 & 12.6 \\
\hline 16 & $\mathrm{BuAc}$ & $\mathrm{ppb}$ & 0.54 & 1.16 & 0.15 & 0.71 & 0.25 & 0.41 & 0.24 & 0.24 & 0.18 & 0.15 & 0.17 & 0.38 & 0.31 & 24.8 \\
\hline 17 & TVOC & $\mu \mathrm{g} / \mathrm{m}^{3}$ & 1,375 & 1,452 & 1,115 & 1,554 & 1,204 & 1,390 & 1,261 & 1,703 & 1,440 & 1,471 & 1,439 & 1,400 & 163 & 3.52 \\
\hline
\end{tabular}

Bold-phased values denote those exceeding the emission guideline levels designated by the indoor pollution regulation guideline (in case of PM) or the malodor prevention law of Korea [5].

during cooking activities in a closed indoor environment. A summary of the measurements made is provided in Table 3.

For $\mathrm{PM}_{10}$ and TVOCs, high concentrations appeared to be generated consistently from each experiment with mean measured values of $7110 \mu \mathrm{g} \mathrm{m}^{-3}$ and $1400 \mu \mathrm{g} \mathrm{m}^{-3}$, respectively. For the reader's reference, these measurement data can be compared to the corresponding IAQ guidelines of 100 and $400 \mu \mathrm{g} \mathrm{m}^{-3}$, respectively, which were set by the Korean Ministry of Environment [5]. The TVOC concentrations generated by fish frying appear to be several times higher than those observed from other source activities (e.g., the combustion of different BBQ charcoals) in our previous study [6]. In addition, a number of aldehyde species well known for offensive odorants such as acetaldehyde, valeraldehyde, and isovaleraldehyde were seen at the range over two orders of magnitude with mean concentrations of 99.3, 12.2, and $3.96 \mathrm{ppb}$, respectively. As such, these aldehyde species exceeded the guidelines set for malodor prevention law by the Korean Ministry of Environment [5].

A principal component analysis (PCA) of the data collected (using OriginPro 9.1, OriginLab Corporation) demonstrated that the first two principal components accounted for $75 \%$ of the variability in the system. The first component was predominantly associated with aldehyde and TVOC content; the second competent was associated mainly with the aromatic component. However these relationships were not exclusive and most of the components showed some mutual correlation; the correlations determined between all components from the principal component analysis are shown in Table 4. Propionaldehyde stands out as having very

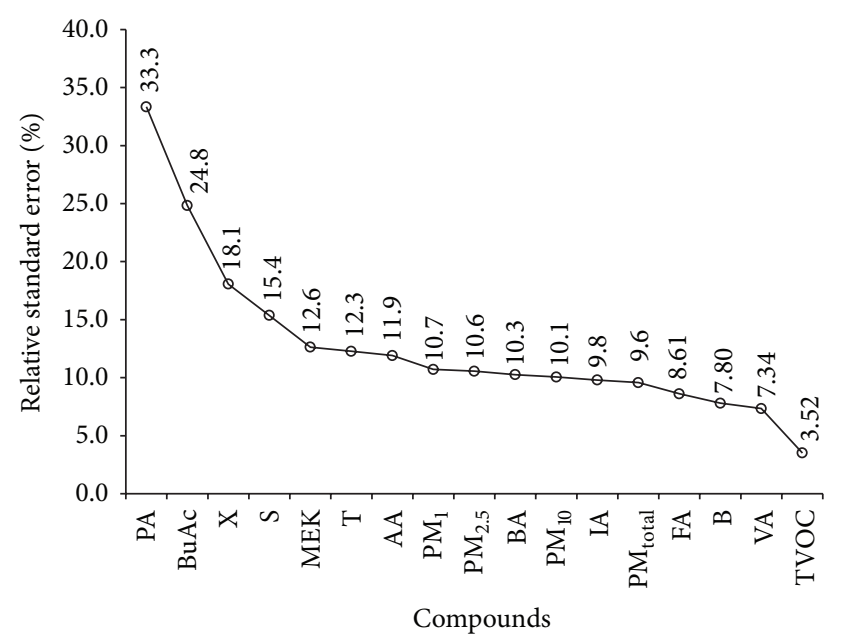

FIgURE 2: The relative standard error (RSE, \%) values of the concentrations of target compounds obtained from a total of 11 repeat pan fryings of mackerel samples.

low or negative correlations with most of the other components; this agrees well with observations of its poor reproducibility as seen in Figure 2. There is substantial correlation between the different PM measurements and also between the different aromatic components. TVOC also shows high correlation with many of the individual components, as would be expected since they are contributory components to the TVOC load.

Cluster analysis (CA) was performed additionally to evaluate the relationship between the measured PM and VOCs 
TABLE 4: Correlation matrix resulting from the principal component analysis of the data produced in this study.

\begin{tabular}{|c|c|c|c|c|c|c|c|c|c|c|c|c|c|c|c|c|}
\hline & $\mathrm{PM}_{1}$ & $\mathrm{PM}_{2.5}$ & $\mathrm{PM}_{10}$ & FA & AA & PA & $\mathrm{BA}$ & IA & VA & B & $\mathrm{T}$ & $\mathrm{X}$ & S & MEK & $\mathrm{BuAc}$ & TVOC \\
\hline TSP & 0.97 & 0.97 & 0.99 & 0.50 & 0.34 & 0.03 & 0.74 & 0.28 & 0.71 & -0.03 & 0.25 & -0.05 & -0.27 & 0.41 & 0.17 & 0.66 \\
\hline $\mathrm{PM}_{1}$ & - & 1.00 & 0.99 & 0.55 & 0.32 & 0.13 & 0.80 & 0.27 & 0.82 & -0.02 & 0.37 & -0.04 & -0.21 & 0.46 & 0.14 & 0.76 \\
\hline $\mathrm{PM}_{2.5}$ & & - & 0.99 & 0.55 & 0.32 & 0.12 & 0.80 & 0.27 & 0.81 & -0.02 & 0.36 & -0.04 & -0.22 & 0.45 & 0.15 & 0.76 \\
\hline $\mathrm{PM}_{10}$ & & & - & 0.52 & 0.33 & 0.08 & 0.77 & 0.27 & 0.76 & -0.03 & 0.30 & -0.04 & -0.24 & 0.42 & 0.15 & 0.71 \\
\hline FA & & & & - & 0.54 & -0.05 & 0.64 & 0.37 & 0.64 & 0.31 & 0.41 & 0.34 & 0.18 & 0.36 & 0.06 & 0.71 \\
\hline AA & & & & & - & -0.71 & 0.59 & 0.94 & 0.48 & 0.51 & 0.54 & 0.60 & 0.27 & 0.76 & 0.63 & 0.58 \\
\hline PA & & & & & & - & -0.05 & -0.78 & 0.13 & -0.53 & 0.02 & -0.68 & -0.54 & -0.30 & -0.58 & -0.08 \\
\hline BA & & & & & & & - & 0.49 & 0.96 & 0.23 & 0.53 & 0.10 & 0.01 & 0.73 & 0.21 & 0.97 \\
\hline IA & & & & & & & & - & 0.39 & 0.60 & 0.54 & 0.71 & 0.47 & 0.74 & 0.63 & 0.52 \\
\hline VA & & & & & & & & & - & 0.05 & 0.54 & -0.03 & -0.06 & 0.63 & 0.05 & 0.92 \\
\hline B & & & & & & & & & & - & 0.45 & 0.91 & 0.67 & 0.57 & 0.56 & 0.41 \\
\hline $\mathrm{T}$ & & & & & & & & & & & - & 0.40 & 0.05 & 0.85 & 0.49 & 0.58 \\
\hline $\mathrm{X}$ & & & & & & & & & & & & - & 0.68 & 0.46 & 0.61 & 0.28 \\
\hline S & & & & & & & & & & & & & - & 0.08 & 0.01 & 0.19 \\
\hline MEK & & & & & & & & & & & & & & - & 0.68 & 0.73 \\
\hline $\mathrm{BuAc}$ & & & & & & & & & & & & & & & - & 0.24 \\
\hline TVOC & & & & & & & & & & & & & & & & - \\
\hline
\end{tabular}

from pan frying fish samples in a closed room. Separation of variables into the two main clusters is plotted in Figure 3 as a dendrogram: (I) $\mathrm{PM}_{1}, \mathrm{PM}_{2.5}, \mathrm{PM}_{10}, \mathrm{VA}, \mathrm{BA}$, and $\mathrm{T}$ clusters; and (II) IA, B, MEK, X, S, and BuAc. These results are highly comparable to the patterns derived by the PCA discussed above as they identify correlations between the same pollutants groupings.

To learn more about the pollution induced by cooking, it is necessary to examine and evaluate chemical characteristics in PMs generated from pan frying fish samples. The results of multivariate statistical analysis (PCA and CA) confirm distinctly different associations among the studied PMs and VOCs; this suggests that parts of PMs could be formed by secondary aerosol production, possibly from VA, BA, and $\mathrm{T}$, following the frying during the residence time of these compounds in air. Thus, we are planning to conduct future work in which the pollutants released from pan frying fish samples are quantified accurately in the atmospheric deposition collected in a closed room in the period after pan frying.

3.2. Representativeness of IAQ Parameters. In many countries, a list of common indoor air pollutants (e.g., $\mathrm{CO}_{2}$ ) is selected for IAQ assessment (e.g., [4]). Because of several issues (e.g., technical difficulties, such as maintenance of QA, cost, and limited resources), efforts have continuously been made to reduce or shorten the list of IAQ parameters while maintaining the representativeness of the measurement but identifying key marker components of IAQ. In this study, we attempted to examine the role of reproducibility as the performance index for such marker compounds which could be used in addition to common criteria (e.g., sensitivity, specificity, and predictability).

For the purpose of our study, we evaluated the reproducibility of each measure pollutant in terms of relative standard error (RSE, \%). Figure 2 depicts the results of this comparison. The RSE values of most pollutant species were generally around $10 \%$ (e.g., $<10 \%$ for benzene and some aldehydes and $>10 \%$ for the other compounds). TVOC recorded the best reproducibility (RSE value of $3.2 \%(n=11)$ ). Note that the experimental uncertainties are controlled not only by the common variables in the analysis of airborne pollutants but also by all other variables involved in the sample treatment, preparation, and cooking procedures, especially the variation in the properties of the mackerel themselves (weight, surface area, and composition). However, this study only tests reproducibly under the very similar conditions to facilitate VOC emissions as described above. The results show that the measurement can be quite irreproducible, even under the constant conditions tested in the paper. It is true that changes in other conditions such as air flow would make a difference to the measured results, but these have not been tested here since it would not have been a simple task to deconvolve these contributions to the reproducibility post hoc, and further the reproducibility may then have been extremely large and may have undermined the usefulness of the study. However, it is important to acknowledge that under real conditions the uncertainty of such measurements would be increased further because of the variations in ventilation conditions at the cooking location and the size and geometry of the room.

These confounding factors, notwithstanding the reproducibilities found in this study, appear to be relatively consistent. TVOC would be a good candidate as a marker of IAP because it exhibited the most reproducible concentrations under field conditions. However, although a technical definition of TVOC has been proposed as sum of VOCs detected within the chromatographic VOC window [7], its reliability has been questioned due to the way in which different measurement systems realize this quantity [8] and the biases that this would therefore cause. Moreover, 


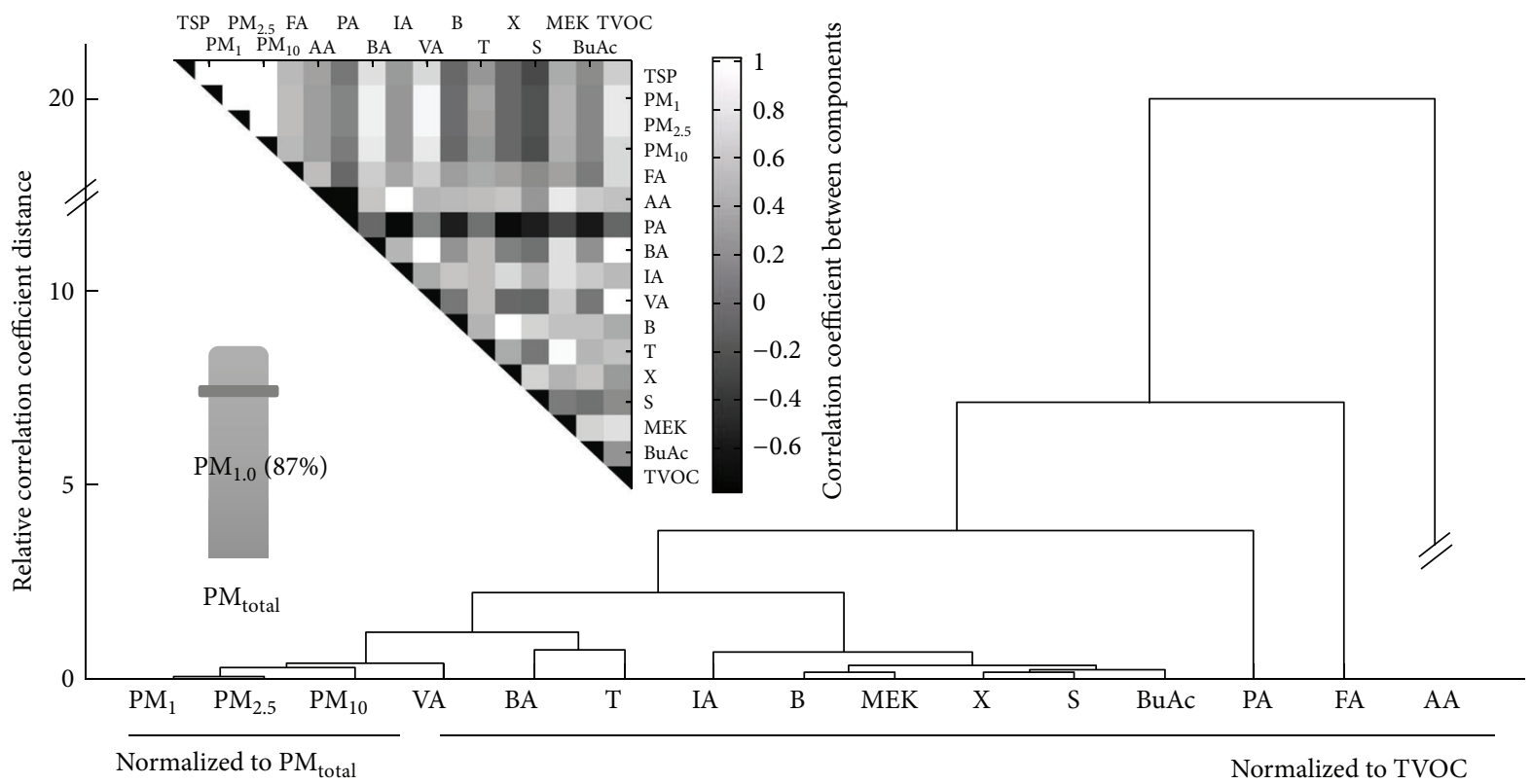

FIGURE 3: Hierarchical clustering analysis of the concentrations of target compounds obtained from a total of 11 repeat pan fryings of mackerel samples (note: $\mathrm{PM}_{1}, \mathrm{PM}_{2.5}$, and $\mathrm{PM}_{10}$ were normalized to $\mathrm{PM}_{\text {total }}$ and volatile organic compounds (VOCs) were normalized to TVOC).

its representativeness has been challenged by a number of missing, but important, components such as low molecular weight reactive aldehydes (e.g., formaldehyde), intermediary reactants, and some volatile odorants at low threshold level [9-12]. Hence, it might be preferable to assign a specific subset of "marker" VOCs which are most likely to be stable and long-lived in air. Thus, their analysis should be well known and characterized in such a way that coherent SI traceable analytical measurements can be produced. Other compounds may undergo reactions in air at different rates depending on ambient conditions and therefore would not be suitable markers. When defining such marker compounds and threshold concentrations for IAQ, it is also important to standardize sampling conditions to ensure as far as possible consistency of the measurand.

\section{Summary and Conclusions}

In this study, a set of VOCs and offensive odorants released from the pan frying of fish samples was measured and their reproducibility was assessed using a total of 11 repeat experiments. Among all of the quantities evaluated, TVOC showed the lowest reproducibilities with an RSE value of $3.2 \%$. The other pollutant species showed reproducibilities of around $10 \%$. The results of our study suggest that TVOC can be used as highly meaningful marker of IAQ, although to ensure the SI traceability of the IAG parameters measured it may be preferable to select a few well-defined VOCs instead of TVOC.

\section{Summary of the Practical Implications}

(i) The status of indoor air pollution (IAP) is an important factor to assess its health impact on the residents. (ii) The reproducibility between IAP variables is assessed critically by a series of repetitive experiments.

(iii) The relative importance between IAP variables is clearly distinguished when measured repeatedly.

\section{Conflict of Interests}

The authors reported no conflict of interests or financial interests.

\section{Acknowledgments}

This research was supported by the Basic Science Research Program through the National Research Foundation of Korea (NRF) funded by the Ministry of Science, ICT and Future Planning (Grant no. 2013-004624). The corresponding author also acknowledges the support of "Cooperative Research Program for Agriculture Science \& Technology Development (Project title: Study on Model Development to Control Odor from Pigpen; Project no. PJ01052101)," Rural Development Administration, Republic of Korea.

\section{References}

[1] K.-H. Kim, S. K. Pandey, E. Kabir, J. Susaya, and R. J. C. Brown, "The modern paradox of unregulated cooking activities and indoor air quality," Journal of Hazardous Materials, vol. 195, pp. $1-10,2011$.

[2] M. G. de Verdier, U. Hagman, R. K. Peters, G. Steineck, and E. Övervik, "Meat, cooking methods and colorectal cancer: a casereferent study in Stockholm," International Journal of Cancer, vol. 49, no. 4, pp. 520-525, 1991.

[3] I. T. S. Yu, Y.-L. Chiu, J. S. K. Au, T.-W. Wong, and J.-L. Tang, "Dose-response relationship between cooking fumes exposures 
and lung cancer among Chinese nonsmoking women," Cancer Research, vol. 66, no. 9, pp. 4961-4967, 2006.

[4] P.-S. Hui, K.-W. Mui, and L.-T. Wong, "Influence of indoor air quality (IAQ) objectives on air-conditioned offices in Hong Kong," Environmental Monitoring and Assessment, vol. 144, no. 1-3, pp. 315-322, 2008.

[5] Korean Ministry of Environment (KMOE), Annual Report of Ambient Air Quality in Korea, KMOE, 2008.

[6] E. Kabir, K.-H. Kim, J.-W. Ahn, O.-F. Hong, and J.-R. Sohn, "Barbecue charcoal combustion as a potential source of aromatic volatile organic compounds and carbonyls," Journal of Hazardous Materials, vol. 174, no. 1-3, pp. 492-499, 2010.

[7] European Collaborative Action ECA-IAQ, Total Volatile Organic Compounds TVOC in Indoor Air Quality Investigations, no. 19, European Commission, Brussels, Belgium, 1997.

[8] E. Massold, A. Riemann, T. Salthammer, W. Schwampe, E. Uhde, and M. Wensing, "Comparison of TVOC by GC/MS with direct reading instruments," in Proceedings of the Healthy Buildings, O. Seppänen and J. Sateri, Eds., vol. 4, pp. 67-72, Helsinki, Finland, 2000.

[9] M. Laska and R. A. Hudson, "A comparison of the detection thresholds of odour mixtures and their components," Chemical Senses, vol. 16, no. 6, pp. 651-662, 1991.

[10] P. Wolkoff and G. D. Nielsen, "Organic compounds in indoor air-their relevance for perceived indoor air quality?” Atmospheric Environment, vol. 35, no. 26, pp. 4407-4417, 2001.

[11] K.-H. Kim, "Experimental demonstration of masking phenomena between competing odorants via an air dilution sensory test," Sensors, vol. 10, no. 8, pp. 7287-7302, 2010.

[12] K.-H. Kim, "The averaging effect of odorant mixing as determined by air dilution sensory tests: a case study on reduced sulfur compounds," Sensors, vol. 11, no. 2, pp. 1405-1417, 2011. 

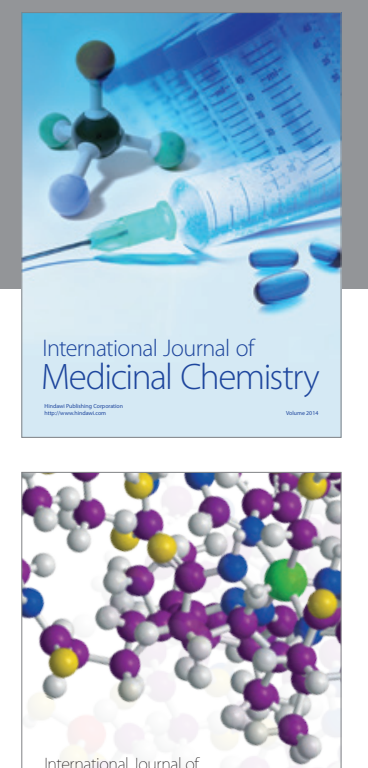

\section{Carbohydrate} Chemistry

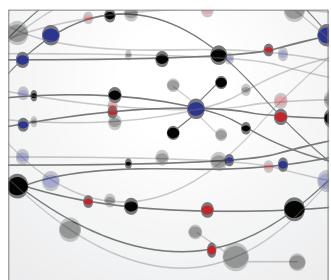

The Scientific World Journal
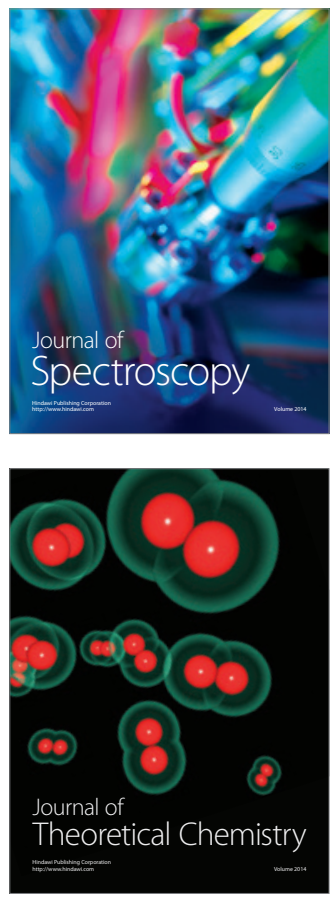
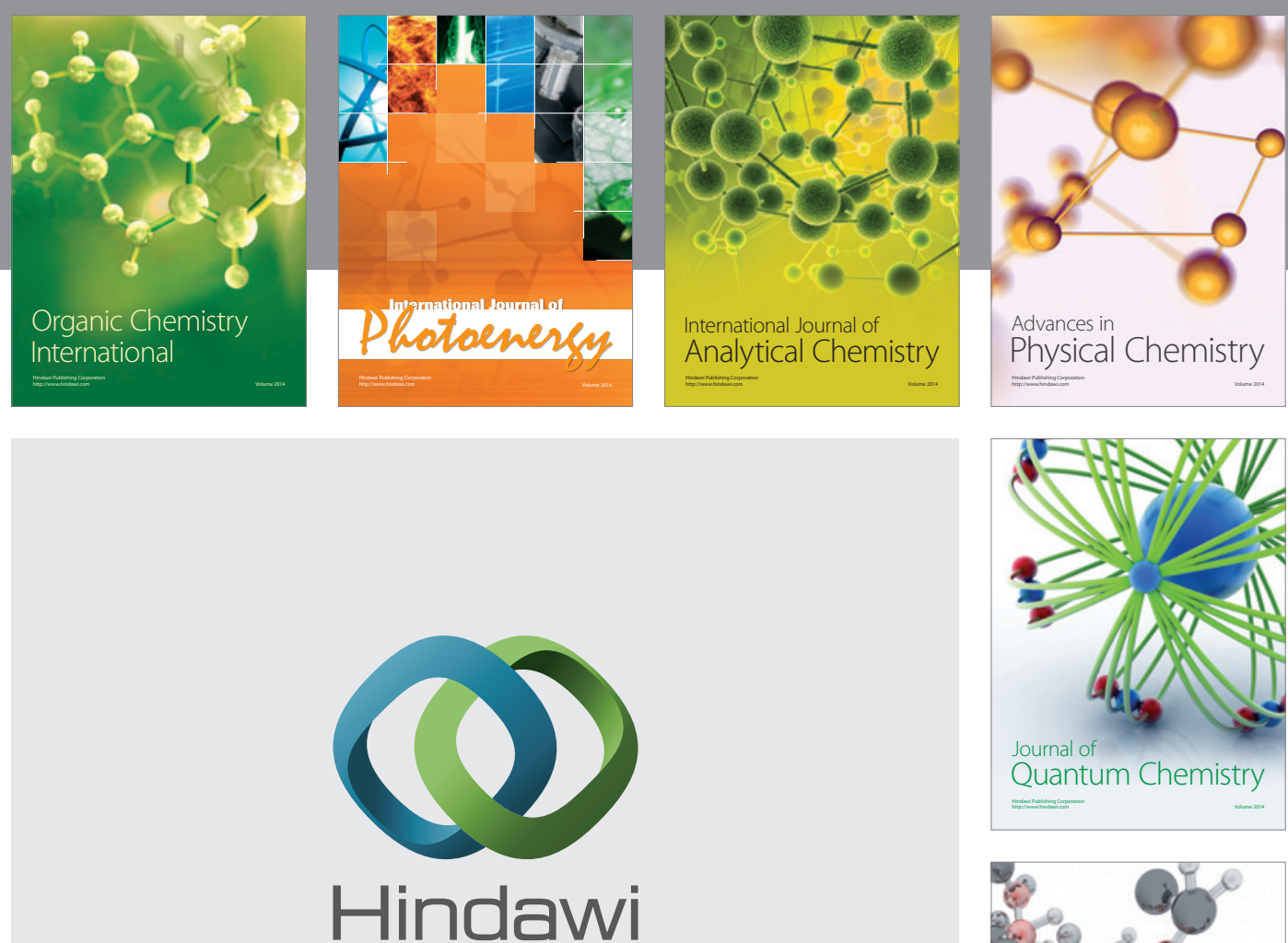

Submit your manuscripts at

http://www.hindawi.com

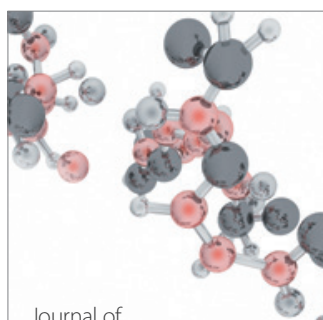

Analytical Methods

in Chemistry

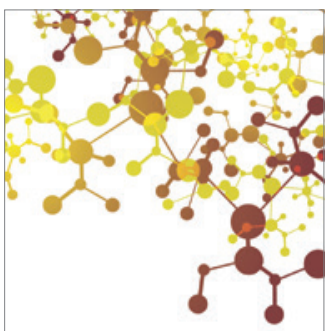

Journal of

Applied Chemistry

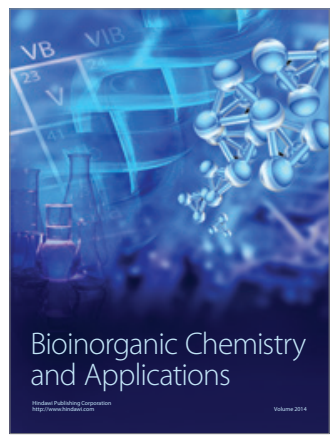

Inorganic Chemistry
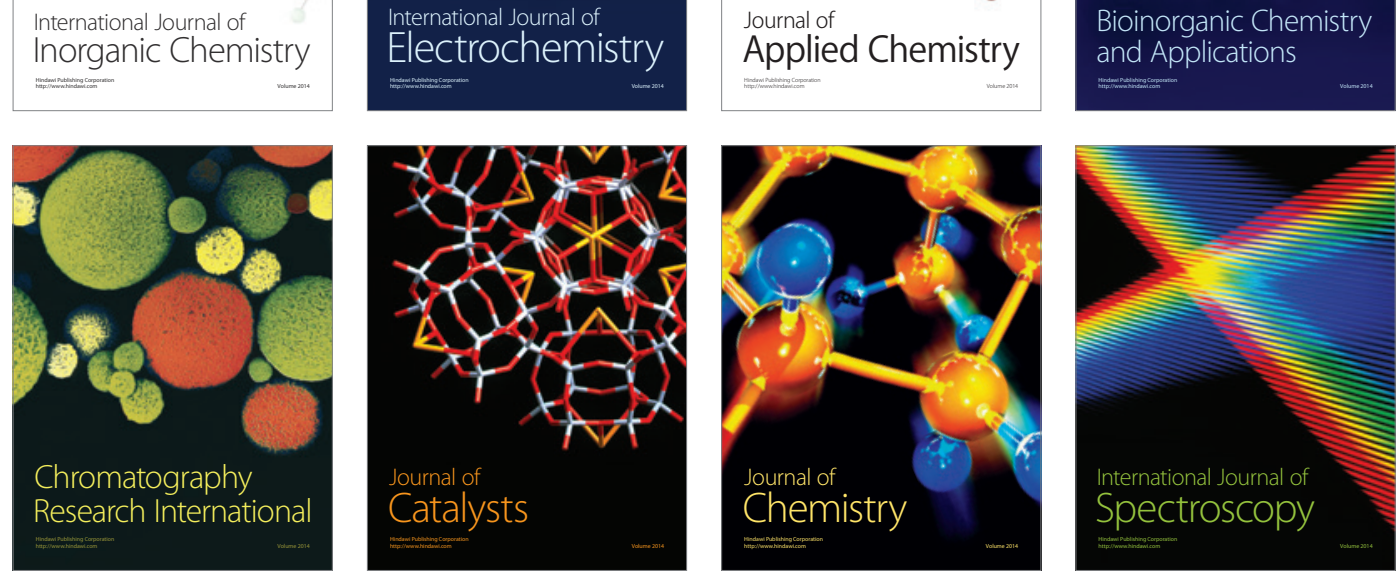